\title{
Laryngeal Dysfunction and Acute Organophosphorus Poisoning
}

\author{
Chulananda Goonasekera ${ }^{1} \odot$, Lakshman Karalliedde ${ }^{2} \odot$
}

Keywords: Acute poisoning intensive care unit, Critical care, Intensive care unit mortality, Intensive care unit outcomes, Respiratory distress, Toxicology, Toxidrome.

Indian Journal of Critical Care Medicine (2022): 10.5005/jp-journals-10071-24107

Organophosphorus pesticides (OP) poisoning is an ongoing health issue globally because of its wide use in the agriculture industry and its regrettable use as a chemical weapon. ${ }^{1,2}$ There is voluminous literature on its causation and the phases of neurological complications.

In this journal edition, Mani et al. ${ }^{3}$ describe a spectrum of laryngeal abnormalities in a cohort of patients who needed intensive care due to acute organophosphorus and carbamate poisoning. The patients who required laryngeal intubation or tracheotomy were extubated/decannulated after assessing for readiness for extubation/decannulation. This assessment was done using a standard local protocol that included two assessments of muscle function (proximal and neck muscle). They report unilateral or bilateral vocal cord paresis or palsy and aspiration, subglottic stenosis, tracheal stenosis, or arytenoid granuloma in patients who have developed hoarseness of voice or stridor following extubation. They found laryngeal dysfunction to be significantly associated with the ingestion of dimethyl organophosphorus compounds and the quantum consumed. Patients with laryngeal dysfunction require an extended hospital stay. They make a realistic proposal to seek assistance/guidance from laryngeal specialists to mitigate this sequel.

Isolated laryngeal paralysis with unilateral or bilateral vocal cord palsy reported in adults and children, especially in acute and intermediate phases, was considered as an indication for intubation or a contributor for difficult extubation. ${ }^{4-8}$ This laryngeal dysfunction is reported to undergo full self-recovery within 2-3 weeks. Its diagnosis may require laryngeal electromyography ${ }^{6}$ and emergency laryngoscopy or bronchoscopy. ${ }^{4,7}$ Therefore, extra vigilance is required to exclude laryngeal involvement, especially in acute and intermediate phases of the OP poisoning evolution when respiratory distress or stridor is observed.

Tracheal reintubation after planned extubation is a relatively common event in critically ill patients. Multiple factors contribute are as follows: obesity, obstructive sleep apnea, major head/ neck and upper airway surgery, and cervical spine procedures. Extubation failure follows the loss of upper airway patency due to issues such as edema, soft tissue collapse, and laryngospasm, frequently resulting in upper airway obstruction. Planning for tracheal extubation is a critical component of a successful airway management strategy, mainly when dealing with situations at increased risk of extubation failure and in patients with difficult airways monitoring. ${ }^{9}$ The OP-related laryngeal dysfunction reported in this journal calls for the consideration of a laryngeal function assessment to minimize extubation failure in patients who require intensive care following OP poisoning. In this
${ }^{1}$ Department of Anaesthetics, King's College Hospital NHS Foundation Trust, Institute of Childhealth, University College London, London, England, United Kingdom

${ }^{2}$ Department of Anaesthesiology, Faculty of Medicine, Peradeniya, Sri Lanka

Corresponding Author: Chulananda Goonasekera, Department of Anaesthetics, King's College Hospital NHS Foundation Trust, Institute of Childhealth, University College London, London, England, United Kingdom, Phone: +7825491319, e-mail: cgoonase@gmail.com

How to cite this article: Goonasekera C, Karalliedde L. Laryngeal Dysfunction and Acute Organophosphorus Poisoning. Indian J Crit Care Med 2022;26(2):155-156.

Source of support: Nil

Conflict of interest: None

context, including laryngeal electromyography in extubation protocol would add insight and reduce the distressing reintubation needs.

Extubation failure following prolonged endotracheal intubation in adult intensive care has received extensive discussion in the literature for decades. Vocal cord paresis or paralysis has been recognized as a contributory factor, and it is usually symmetrical. Cord paresis is associated with arytenoid and posterior commissure edema and erythema, leading to posterior commissure stenosis. The etiology could be mechanical, i.e., inflammation initiated by the endotracheal tube and its movement against the rear half of the endolarynx. When mucosal ulceration and granulation tissue are superimposed on the immobilized cords, interarytenoid scarring may lead to chronic stenosis. These complications have already received the attention of the laryngeal specialists. ${ }^{10}$

In some centers, direct laryngoscopy is performed to evaluate laryngeal damage in the patient who had translaryngeal intubation at the time of extubation. The typical pattern of laryngeal injury was seen, with mucosal ulcerations and the posterior-medial aspects of both vocal cords and varying degrees of laryngeal edema. Although the performance of a tracheostomy and the presence of neuromotor activity were associated with the severity of trans laryngeal intubation related to laryngeal damage, this resolves within 4 weeks in most patients and appears not to contribute to the development of adverse effects at subsequent extubation. ${ }^{11}$ Tracheostomy seems the only resolution available to allow selfrecovery of the laryngeal dysfunction in these critically ill patients without OP poisoning.

(O) The Author(s). 2022 Open Access This article is distributed under the terms of the Creative Commons Attribution 4.0 International License (https://creativecommons. org/licenses/by-nc/4.0/), which permits unrestricted use, distribution, and non-commercial reproduction in any medium, provided you give appropriate credit to the original author(s) and the source, provide a link to the Creative Commons license, and indicate if changes were made. The Creative Commons Public Domain Dedication waiver (http://creativecommons.org/publicdomain/zero/1.0/) applies to the data made available in this article, unless otherwise stated. 
In general, respiratory complications occur during tracheal intubation and extubation, associated with significant morbidity and mortality. This should not be so. Tracheal intubation is not a novel procedure, and there are texts on guidelines for safe and effective intubation across the world. ${ }^{12}$ There have also been several proactive educational workshops to decrease the occurrence of adverse events following tracheal intubation. A similar and proactive approach is in the acquisition process to minimize tracheal extubation-related complications. ${ }^{13}$ However, the implementation of guidelines for difficult airway management supported by proactive education has contributed to the decreased rate of respiratory adverse events occurring during tracheal intubation. ${ }^{14}$

Despite the reports of laryngeal dysfunction being infrequent, they certainly should raise concern proactively as it is an unpleasant complication of OP poisoning. Its onset with respiratory difficulty in the early phases of poisoning may require translaryngeal intubation as a rescue maneuver. Its occurrence at extubation following a period of translaryngeal intubation may warrant a tracheostomy as a therapeutic maneuver. This is because laryngeal dysfunction at this late stage could result from mechanical damage/irritation of translaryngeal intubation or a late phase complication of OP poisoning or both.

Perhaps it may be time to evaluate the role of electromyography of the laryngeal and other muscles involved in respiration during the illness. This is possibly a multidisciplinary approach with laryngologists and neurologists, and electrophysiologists. Would there be a possibility to consider a tracheostomy as the most suitable way for providing ventilation at the very onset of muscle paralysis or even at the beginning with the onset of signs of poisoning? The need is to get back to the drawing board and plan protocols to avoid this unwanted complication that follows an apparent therapeutic maneuver.

\section{ORCID}

Chulananda Goonasekera @ https://orcid.org/0000-0002-9754-6477 Lakshman Karalliedde (1) https://orcid.org/0000-0002-6519-258X

\section{References}

1. Hulse EJ, Haslam JD, Emmett SR, Woolley T. Organophosphorus nerve agent poisoning: managing the poisoned patient. $\mathrm{Br} J$ Anaesth 2019;123(4):457-463. DOI: 10.1016/j.bja.2019.04.061.
2. Ranjan A, Jindal T. Overview of organophosphate compounds. In: Ranjan A, Jindal T, editors. Toxicology of organophosphate poisoning: new insights. Cham: Springer International Publishing; 2022. p. 1-25.

3. Mani GS, Mathews SS, Victor P, Peter JV, Yadav B, Albert RRA. Laryngeal Dysfunction in Acute Organophosphorus and Carbamate Poisoning. Indian J Crit Care Med 2022;26(2):167-173.

4. Thompson JW, Stocks RM. Brief bilateral vocal cord paralysis after insecticide poisoning. A new variant of toxicity syndrome. Arch Otolaryngol Head Neck Surg 1997;123(1):93-96. DOI: 10.1001/archotol. 1997.01900010103016.

5. Indudharan R, Win MN, Noor AR. Laryngeal paralysis in organophosphorous poisoning. J Laryngol Otol 1998;112(1):81-82. DOI: $10.1017 / \mathrm{s} 0022215100139969$.

6. Jin $\mathrm{YH}$, Jeong TO, Lee JB. Isolated bilateral vocal cord paralysis with intermediate syndrome after organophosphate poisoning. Clin Toxicol (Phila) 2008;46(5):482-484. DOI: 10.1080/15563650701704842.

7. Vaidya S, Salvi M, Karnik N, Sunder U, Yeolekar M. Life threatening stridor due to bilateral recurrent laryngeal nerve palsy as an isolated manifestation of intermediate syndrome. J Assoc Physicians India 2002;50:454-455. PMID: 11922245.

8. de Silva HJ, Sanmuganathan PS, Senanayake N. Isolated bilateral recurrent laryngeal nerve paralysis: a delayed complication of organophosphorus poisoning. Hum Exp Toxicol 1994;13(3):171-173. DOI: 10.1177/096032719401300306.

9. Cavallone LF, Vannucci A. Review article: extubation of the difficult airway and extubation failure. Anesth Analg 2013;116(2):368-383. DOI: 10.1213/ANE.0b013e31827ab572.

10. Whited RE. Laryngeal dysfunction following prolonged intubation. Ann Otol Rhinol Laryngol 1979;88(4 Pt 1):474-478. DOl: $10.1177 / 000348947908800405$.

11. Colice GL, Stukel TA, Dain B. Laryngeal complications of prolonged intubation. Chest 1989;96(4):877-884. DOI: 10.1378/chest.96.4.877.

12. Higgs A, McGrath BA, Goddard C, Rangasami J, Suntharalingam G, Gale R, et al. Guidelines for the management of tracheal intubation in critically ill adults. Br J Anaesth 2018;120(2):323-352. DOI: 10.1016/j. bja.2017.10.021.

13. Cooper RM, O'Sullivan E, Popat M, Behringer E, Hagberg CA. Difficult airway society guidelines for the management of tracheal extubation. Anaesthesia 2013;68(2):217. Available from: https:// association ofanaesthetists-publications.onlinelibrary.wiley.com/ doi/10.1111/anae.12139.

14. Jaber $S$, Jung $B$, Corne $P$, et al. An intervention to decrease complications related to endotracheal intubation in the intensive care unit: a prospective, multiple-center study. Intensive Care Med 2010;36(2):248-255. DOI: 10.1007/s00134-009-1717-8. 